\title{
Reproducibility of Novel Soft-Tissue Landmarks on Three- Dimensional Human Facial Scan Images in Caucasian and Asian
}

\author{
Zhouxiao Li ${ }^{1}$ (D) Riccardo Enzo Giunta ${ }^{1}$ Konstantin Frank ${ }^{1} \cdot$ Thilo Ludwig Schenck $^{1}$ • \\ Konstantin Christoph Koban ${ }^{1}$
}

Received: 18 July 2021/Accepted: 10 October 2021/Published online: 26 October 2021

(C) The Author(s) 2021

\begin{abstract}
Background Three-dimensional surface imaging is established in many disciplines for objective facial acquisition regarding anthropometry. Former studies addressed the validation of landmark-based measurements for single race. In order to distinguish racial difference, the reproducibility of the landmark measurements must first be validated.

Objectives Our purpose is to validate the reproducibility of 46 facial soft-tissue landmarks on $x, y, z$ axes to prove their reliability as 3D reference points.

Methods The study included 80 European Caucasian and 80 Chinese volunteers. Standardized 3D surface imaging was performed using Vectra 3D system. Two raters identified and defined 46 landmarks (138 coordinates), then repeatedly 3D-imaged volunteers' facial region in separate sessions. Coordinates' reproducibility of landmarks is divided into three categories $(<0.5 \mathrm{~mm},<1 \mathrm{~mm}$, and $>1$ $\mathrm{mm}$ ) for intra- and inter-rater reproducibility assessments. Results Coordinates' reproducibility of 160 samples was distributed as follows: Intra-rater: $<0.5 \mathrm{~mm}(45 \%),<1$ $\mathrm{mm}$ (42\%), $>1 \mathrm{~mm}$ (13\%); inter-rater: $<0.5 \mathrm{~mm}(31.2 \%)$, $<1 \mathrm{~mm}(42 \%),>1 \mathrm{~mm}(26.8 \%)$. The reproducibility of landmarks in nasal tip region differs slightly between Caucasians and Asians. Compared to females, males typically have higher landmark reproducibility in lip and chin region. However, there were no differences in the reproducibility ranking of landmarks by gender.
\end{abstract}

Zhouxiao Li

Zhouxiao.Li@med.uni-muenchen.de

1 Division of Hand, Plastic and Aesthetic Surgery, University Hospital, LMU Munich, Pettenkoferstraße 8a, 80336 Munich, Germany
Conclusion The majority of the 46 landmarks in the 3D plane are reproducible to $1 \mathrm{~mm}$, which is clinically acceptable. All selected landmarks showed strong consistency across race and gender, suggesting their potential use as reference points in prospective clinical practice.

Level of Evidence IV This journal requires that authors assign a level of evidence to each article. For a full description of these Evidence-Based Medicine ratings, please refer to the Table of Contents or the online Instructions to Authors www.springer.com/00266.

Keywords Facial landmarks · Anthropometry - Threedimensional surface imaging - Ethic and Gender

\section{Introduction}

Three-dimensional surface imaging (3DSI) is an established means of facial analysis for infant facial development and congenital conditions such as cleft lip and palate or alterations of the skull, in facial reconstructive surgery, and for aesthetic facial plastic surgery consultation [1-3]. As a noninvasive technology, it also plays an increasingly important role in evaluating facial morphology. Surface imaging is often used in conjunction with computed tomography (CT) or magnetic resonance imaging (MRI).

Although there are numerous devices for three-dimensional (3D) acquisition, the basis of anthropometric surveying is often a landmark-based approach. Facial surface landmarks are critical to the accuracy of 3D facial morphology measurement and analysis $[4,5]$.

Currently, 3D cameras are promising tools for the assessment of facial soft-tissue morphology with highresolution surface textures. The advantage lies in quickly collecting information and constructing high-resolution 3D 
images, which can accurately capture the subject's facial skin color and surface texture [6-8]. Rendered 3D models may provide benefit for (1) evaluation of pediatric facial development, (2) analysis of facial morphology of patients affected by congenital and acquired pathological factors, (3) facial analysis for patients undergoing facial cosmetic, reconstructive, and orthodontic procedures, and (4) morphological studies on the normalization of facial impairments [9-12].

Facial surface landmarks are critical to the accuracy of 3D morphological assessment. Although there has been much research on the reliability and reproducibility of landmarks on facial 3D images, they are mainly focused on one race and the sample sizes are relatively small. Additionally, many of them do not assess reproducibility, and most of the selected landmarks were traditional reference points that had been validated [7, 13-15]. Any facial morphological analysis based on anatomical landmarks requires highly reproductive and novel reference points across different patient populations. In this study, we aimed to define a number of novel facial soft-tissue landmarks to and assessed their reproducibility using a photogrammetric 3D stereophotography system

\section{Materials and Methods}

\section{Study Sample}

The study involved 80 European Caucasians (40 males, 40 females) and 80 Asian (40 males, 40 females). The age range of Caucasian volunteers was 20 to 50 years (30.49 \pm 5.52 years). The age range of Asian volunteers was 18 to 45 years $(30.36 \pm 2.99$ years). Written informed consent was obtained prior to enrollment. The study was approved by local university ethics committee (REF: 266-13) and conducted in accordance with the Declaration of Helsinki. Exclusion criteria were facial deformities, previous facial surgery, and volunteers diagnosed with epilepsy or other seizure disorders.

\section{D Stereophotography Equipment and Parameters}

All facial 3d scans were captured by the high-resolution Vectra XT 3D Surface Imaging System (Canfield Inc., New Jersey, USA). It is a vertical fixed photography system with six integrated cameras at different angles. Its proprietary illumination system automatically adjusts the focus for optimal face imaging and its $3.5 \mathrm{~mm}$ photographic time reduces artifacts of the Vectra system due to the unconscious displacement of the subject.

\section{Image Sampling Process}

Before taking the photograph, all volunteers were removed from any factors which would interfere with the image modeling: jewelry, glasses, and clothing elements (scarves, hat, etc.). They were asked to remove any hair from the face, forehead, and ears to completely expose the facial area. Male volunteers were asked to shave, while beards would cause image artifacts. The scan was performed in a well-lighted room. All volunteers were asked to sit in the same chair with a fixed backrest, lips kept closed without teeth grinding, and to look directly at the red marker dot on the 3D camera with a neutral facial expression and a natural head position. The lighting was kept under the same control conditions as in our daily work.

\section{D Processing}

All captured images were processed, aligned, and analyzed using the proprietary Mirror ${ }^{\circledR}$ (Canfield Scientific; NJ, USA) [16]. The software was also implemented for providing reference frameworks with the $x, y, z$ axis (sagittal, Y-Z plane; coronal, X-Y plane; and transverse, $\mathrm{X}-\mathrm{Z}$ plane.) by unifying orientation for different images. The entire face was marked and symmetry of the planes was automatically adjusted by the integrated software. The midpoint between two endocanthions was chosen (midintercanthal point) as the origin point. The sagittal plane was referenced to the origin through the midline of the face, the coronal plane was determined to be the average natural head position, and the transverse plane was established to span the origin (Fig 1). The 3D face images were normalized on three planes to obtain comparable $\mathrm{X}, \mathrm{Y}$, and $\mathrm{Z}$ coordinates to assess the reproducibility of the facial landmarks [17].

\section{Data Evaluation}

In routine clinical facial surgery, surgeons will mark various anatomical landmarks for measurement. In this work, two raters identified and defined 46 landmarks based on former reports and the raters placed them separately on 3D facial images and all landmark coordinates were recorded (138 totally) for X,Y, Z axes [18-20]. Their name, abbreviation, and definition are displayed in Table 1 . These landmarks contain some of the most commonly used classic landmarks and the novel landmarks that we found beneficial for facial measurements (Fig 2). Both raters are professional researchers in our department experienced in $3 \mathrm{D}$ anthropometry. One of the raters evaluates the reproducibility of all landmarks in a two-week interval to obtain intra-rater reproducibility. We then compared the two raters' results for inter-rater reproducibility. Based on the 

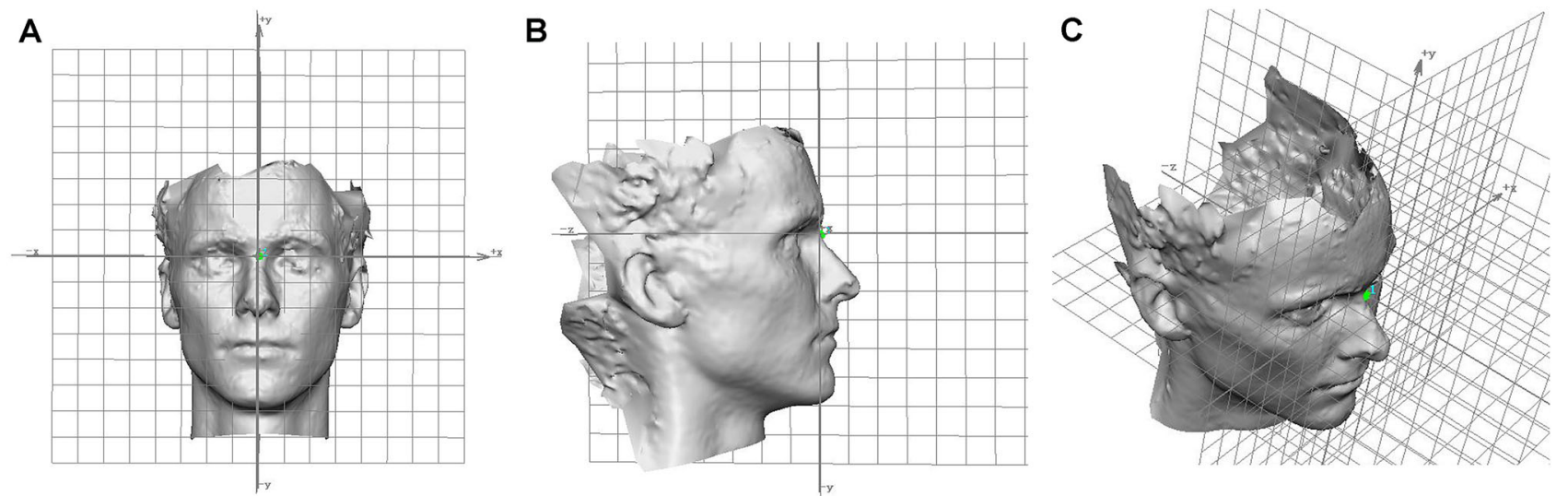

Fig. 1 Standardized 3D facial images on three spatial planes

intra-rater and inter-rater assessment results of 160 volunteer, we calculated the mean and standard deviation for each landmark. The error of the landmarks is presented as the absolute difference in measurement of each landmark on three axes. It is divided into three categories $(<0.5 \mathrm{~mm}$, $<1 \mathrm{~mm}$, and $>1 \mathrm{~mm}$ ). Coordinates with a difference between the measurements of less than $0.5 \mathrm{~mm}$ of all samples are classified as highly reproducible; with a difference between $0.5 \mathrm{~mm}$ and $1 \mathrm{~mm}$ are determined to be moderately reproducible; with a difference above $1 \mathrm{~mm}$ are considered to be poorly reproducible [21, 22]. Both intraand inter-rater evaluations assessed the reproducibility of landmarks of all samples on three planes, divided into race and gender.

\section{Statistical Analysis}

A total of 88320 variables (46 landmarks $\times 160$ subjects $\times 3$ planes $\times 2$ raters $\times 2$ measurements) were analyzed with SPSS Statistics 23.00 (IBM, Armonk, NY, USA). Based on the absolute difference of each landmark on the $\mathrm{x}, \mathrm{y}$, and $\mathrm{z}$ axes, we calculate the total average reproducibility difference using the following formula to: $T=\sqrt{\frac{(\Delta X)^{2}+(\Delta Y)^{2}+(\Delta Z)^{2}}{3}}$, where $T$ is the total average difference, $\Delta X$ is the difference on the $\mathrm{x}$-axis, $\Delta Y$ is the difference on the $\mathrm{y}$-axis, and $\Delta Z$ is the difference on the $\mathrm{z}$ axis. Each variable is first corrected to the median for all volunteers. Bland-Altman plots were carried out for intraand inter-rater reproducibility assessments. For each plot, the difference between the measurements of each landmark coordinate was calculated and the average measurement for that particular coordinate is generated. In Figures 3 and 4, we exhibited the representative coordinates of selected landmarks to illustrate the consistency between high, moderate, and low levels of coordinates measurements in different scenarios. The vertical axis of Bland-Altman plots shows the measurement variance of the selected landmarks, while the horizontal axis shows the average of the measurements. The zero line refers to the subject with zero measurement variance (highest reproducibility). The two dashed lines above and below the zero line indicate the subject with the highest variance between the two measurement sessions.

\section{Results}

\section{Overall Reproducibility}

Table 2 shows the overall results of coordinates' reproducibility gained from intra- and inter-rater results of 160 volunteers. In addition to the overview, we display the results separately according to race and gender. Generally, reproducibility of most assessments was less than $1 \mathrm{~mm}$ (intra-examiner $87 \%$, and inter-examiner $73.2 \%$ ). In the Caucasian subgroups, the intra-examiner was $83.4 \%$ and inter-examiner was $71.1 \%$; in Asian the intra-examiner was $79.7 \%$ and the inter-examiner was $72.5 \%$. Among females, the intra-examiner was $79.7 \%$ and inter-examiner was 69.6\%; among males, the intra-examiner was $82.6 \%$ and the inter-examiner was $73.2 \%$. The highest reproducibility $(<0.5 \mathrm{~mm})$ coordinates were $45 \%$ (intra-rater) and $31.2 \%$ (inter-rater) of the 160 samples. The worst reproducibility $(>1 \mathrm{~mm})$ coordinates accounted for $13 \%$ (intra-rater) and $26.8 \%$ (inter-rater).

The error results of all landmarks on the $\mathrm{x}, \mathrm{y}$, and $\mathrm{z}$ axes after all samples were grouped by gender and race are shown in Tables 3 and 4, respectively (mean and SD). Additionally, we calculated the total error based on the results on each axis for each landmark. The landmarks were ranked from most reproducible to least reproducible for both intra- and inter-examiner assessments. Compared to the intra-rater assessments, we noticed that the corresponding inter-rater results showed poorer reproducibility. 
Table 1 The name and definition of facial landmarks used in this study

\begin{tabular}{|c|c|c|}
\hline $\begin{array}{l}\text { Facial } \\
\text { area }\end{array}$ & Landmarks & Definition \\
\hline \multirow[t]{4}{*}{ Eye } & Em left & Lower margin of the left medial eyebrow end \\
\hline & Em right & Lower margin of the right medial eyebrow end \\
\hline & Endocanthion left (En 1) & The left inner commissure of the palpebral fissure, the right midpoint of the frontonasal suture \\
\hline & Endocanthion right (En r) & The right inner commissure of the palpebral fissure, the right midpoint of the frontonasal suture \\
\hline \multirow[t]{27}{*}{ Nose } & $\begin{array}{l}\text { Alar curvature/Alar crest left } \\
\text { (Ac 1) }\end{array}$ & Alar curvature point (ac) is the point located at the facial insertion of left alar base. \\
\hline & $\begin{array}{l}\text { Alar curvature/Alar crest } \\
\text { right }(\mathrm{Ac} \mathrm{r})\end{array}$ & Alar curvature point (ac) is the point located at the facial insertion of right alar base. \\
\hline & Alare left (Al 1) & The most lateral point on left alar contour \\
\hline & Alare right $(\mathrm{Al} \mathrm{r})$ & The most lateral point on right alar contour \\
\hline & Columella $(\mathrm{Cm})$ & Most anterior and inferior point on apex of nose \\
\hline & $\begin{array}{l}\text { Columella constructed point } \\
\text { (Cc) }\end{array}$ & the midpoint of the columella crest at the level of the nostril top points \\
\hline & Glabella (G) & Most anterior point on midline of forehead \\
\hline & $\begin{array}{l}\text { Highnasal (Hn) or Lownasal } \\
\text { (Ln) }\end{array}$ & The most anterior or posterior point on dorsum of nose between its root and tip \\
\hline & Nasion $(\mathrm{N})$ & Deepest point in middle of frontonasal curve \\
\hline & Nostril base point left (Nb 1) & The lowest point of each nostril or the inferior terminal point of left nostril axis. \\
\hline & Nostril base point right $(\mathrm{Nb} \mathrm{r})$ & The lowest point of each nostril or the inferior terminal point of right nostril axis. \\
\hline & Nostril lateral point left (N1 l) & The junction point of nostril short axis and the lateral margin of left nostril \\
\hline & $\begin{array}{l}\text { Nostril lateral point right }(\mathrm{Nl} \\
\mathrm{r})\end{array}$ & The junction point of nostril short axis and the lateral margin of right nostril \\
\hline & $\begin{array}{l}\text { Nostril medial point right } \\
(\mathrm{Nm} \mathrm{l)}\end{array}$ & The junction point of nostril short axis and the medial margin of left nostril \\
\hline & $\begin{array}{l}\text { Nostril medial point right } \\
(\mathrm{Nm} \mathrm{r})\end{array}$ & The junction point of nostril short axis and the medial margin of right nostril \\
\hline & Nostril top points left (Nt 1 ) & The highest point of each nostril or the superior terminal point of left nostril axis. \\
\hline & Nostril top points right $(\mathrm{Nt} r)$ & The highest point of each nostril or the superior terminal point of right nostril axis. \\
\hline & Ort left & The left Junction of true vertical (TV) and true horizontal $(\mathrm{TH})$ on the alare \\
\hline & Ort right & the right Junction of true vertical (TV) and true horizontal $(\mathrm{TH})$ on the alare \\
\hline & Pronasale (Prn) & Most prominent point on apex of nose \\
\hline & Sellion (Se) & $\begin{array}{l}\text { The most posterior point of the frontonasal soft-tissue contour in the midline of the base of the nasal } \\
\text { root. }\end{array}$ \\
\hline & Sellion’ left (Se' 1) & The left intersections of $\mathrm{TH}[\mathrm{Se}]$ and Dorsal aesthetic lines \\
\hline & Sellion’ right (Se’ r) & The right intersections of $\mathrm{TH}[\mathrm{Se}]$ and Dorsal aesthetic lines \\
\hline & Subnasale (Sn) & Deepest point in nasolabial curvature \\
\hline & Supratip break (Stb) & The joint point of the dorsum and nasal tip \\
\hline & Tip defining point left(TDP 1) & $\begin{array}{l}\text { The left most anterior projection of the tip cartilages, usually corresponding to the apex of the lobular } \\
\text { arch anatomically }\end{array}$ \\
\hline & $\begin{array}{l}\text { Tip defining point right (TDP } \\
\text { r) }\end{array}$ & $\begin{array}{l}\text { The right most anterior projection of the tip cartilages, usually corresponding to the apex of the } \\
\text { lobular arch anatomically }\end{array}$ \\
\hline \multirow[t]{8}{*}{ Mouth } & Cervical (C) & Deepest point at angel of chin and neck \\
\hline & Labrale inferius $(\mathrm{Li})$ & Lower lip vermilion border \\
\hline & Labrale superius $(\mathrm{Ls})$ & Upper lip vermilion border \\
\hline & Menton (Me) & Most inferior point on inferior edge of chin \\
\hline & Stomion(Sto) & The midpoint of the horizontal labial fissure \\
\hline & Sublabiale(Sl) & $\begin{array}{l}\text { The most posterior midpoint on the labiomental soft-tissue contour that defines the border between } \\
\text { the lower lip and the chin. }\end{array}$ \\
\hline & Supramental (Sm) & Deepest point in inferior sublabial concavity \\
\hline & Pogonion (Pg) & Most anterior midpoint of chin \\
\hline
\end{tabular}


Table 1 continued

\begin{tabular}{lll}
\hline $\begin{array}{l}\text { Facial } \\
\text { area }\end{array}$ & Landmarks & Definition \\
\hline Ear & $\begin{array}{l}\text { Postaurale left }(\mathrm{Pa} 1) \\
\text { Postaurale right }(\mathrm{Pa} \mathrm{r})\end{array}$ & $\begin{array}{l}\text { Most posterior point on the free margin of the left ear } \\
\text { Most posterior point on the free margin of the right ear }\end{array}$ \\
& Tragus left (Trg 1) & Most posterior point of auricular tragus left \\
& Tragus right (Trg r) & Most posterior point of auricular tragus right \\
Others & Trichion(Tri) & Intersection of hairline and midline of forehead \\
& Zygion left (Zy 1) & The most lateral point on the outline of left zygomatic arch \\
& Zygion right (Zy r) & The most lateral point on the outline of right zygomatic arch \\
\hline
\end{tabular}

Fig. 2 Nasal soft-tissue landmarks

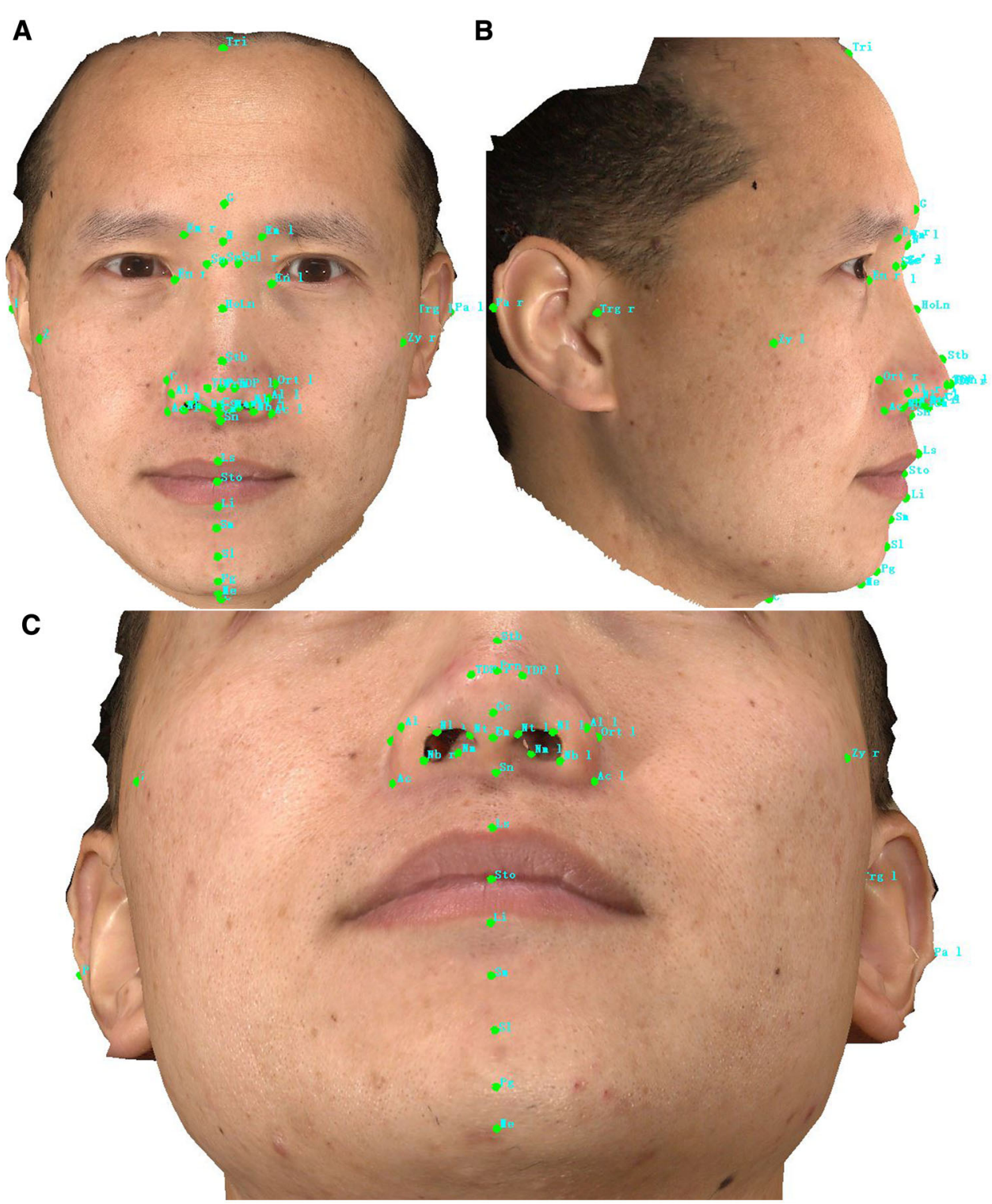




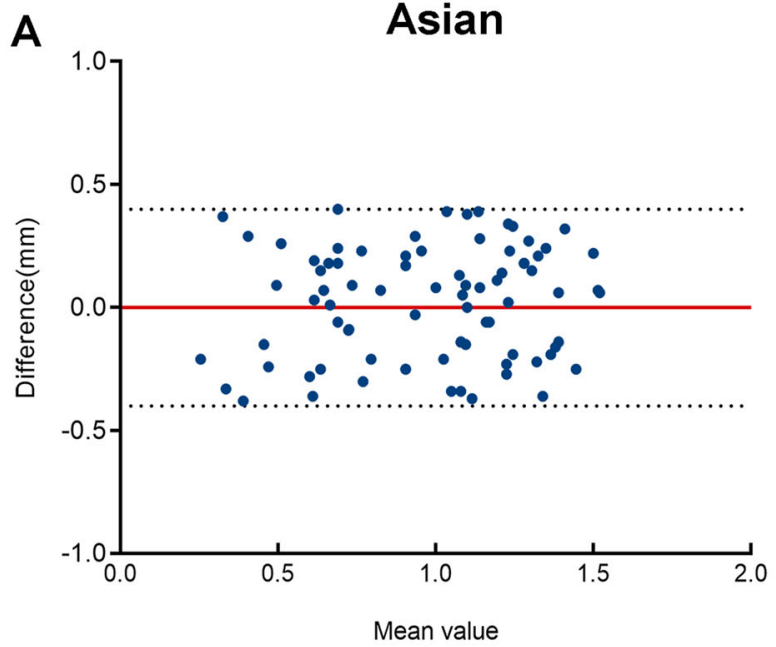

Columella constructed- $X$ axis

B

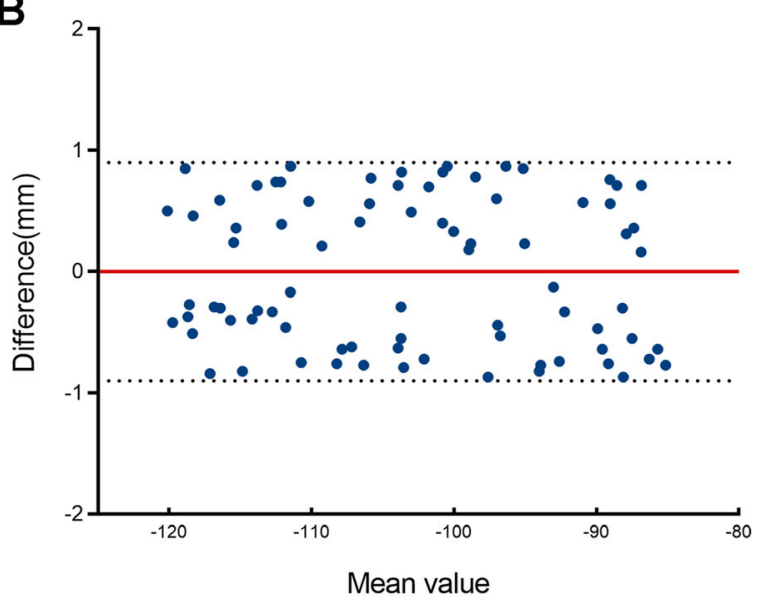

Menton-Y axis

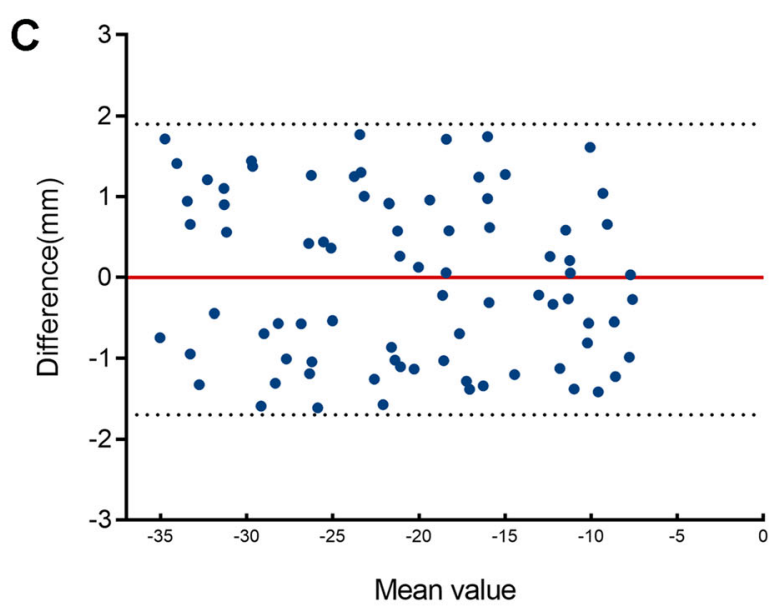

Trichion-Y axis
Caucasian

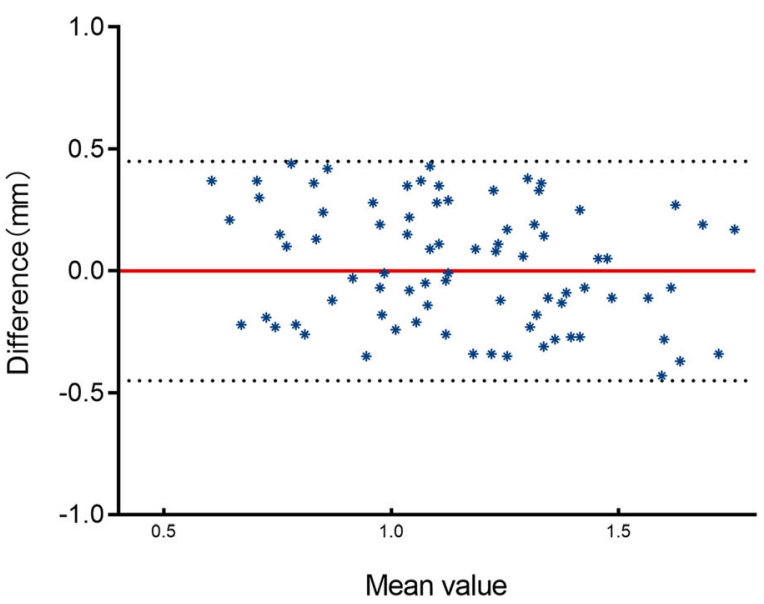

Collumella constructed- $X$ axis

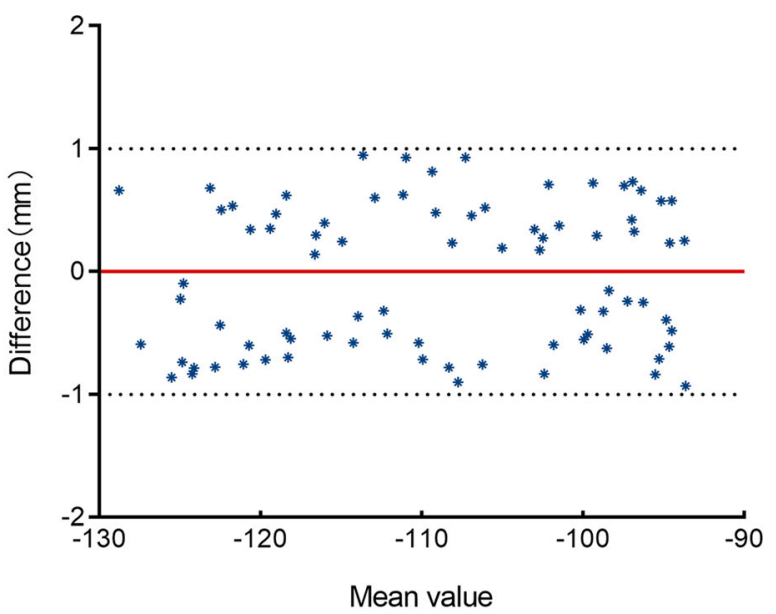

Menton-Y axis

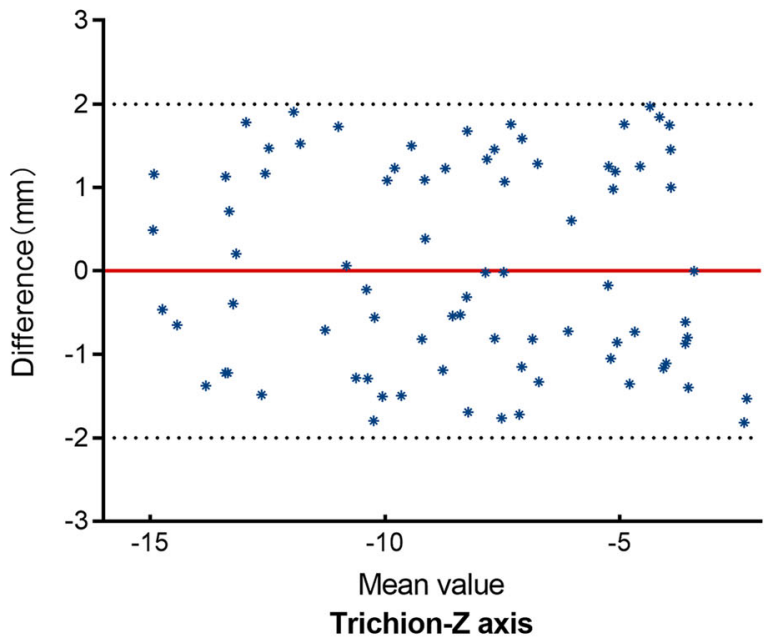

Fig 3 Reproducibility of representative landmarks identification between Caucasian and Asian (intra-rater) 


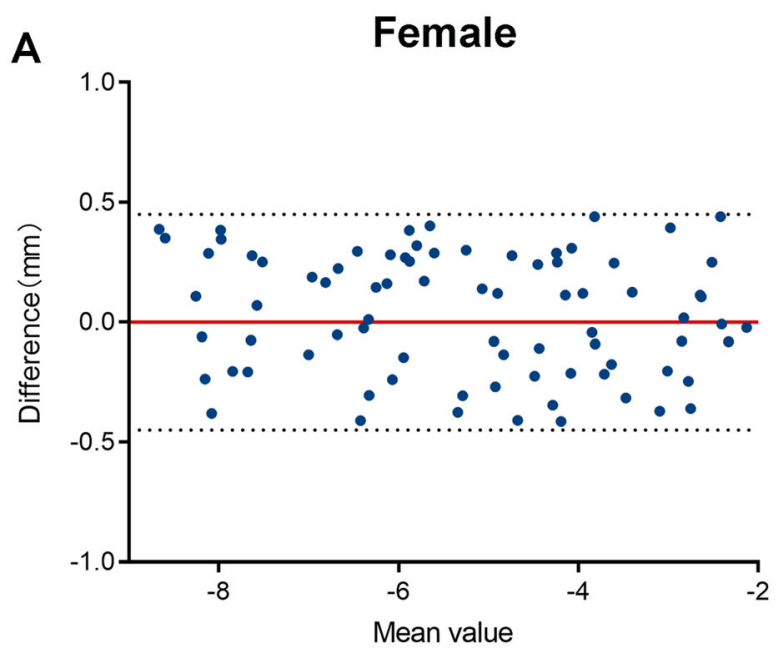

Pronasale-X axis
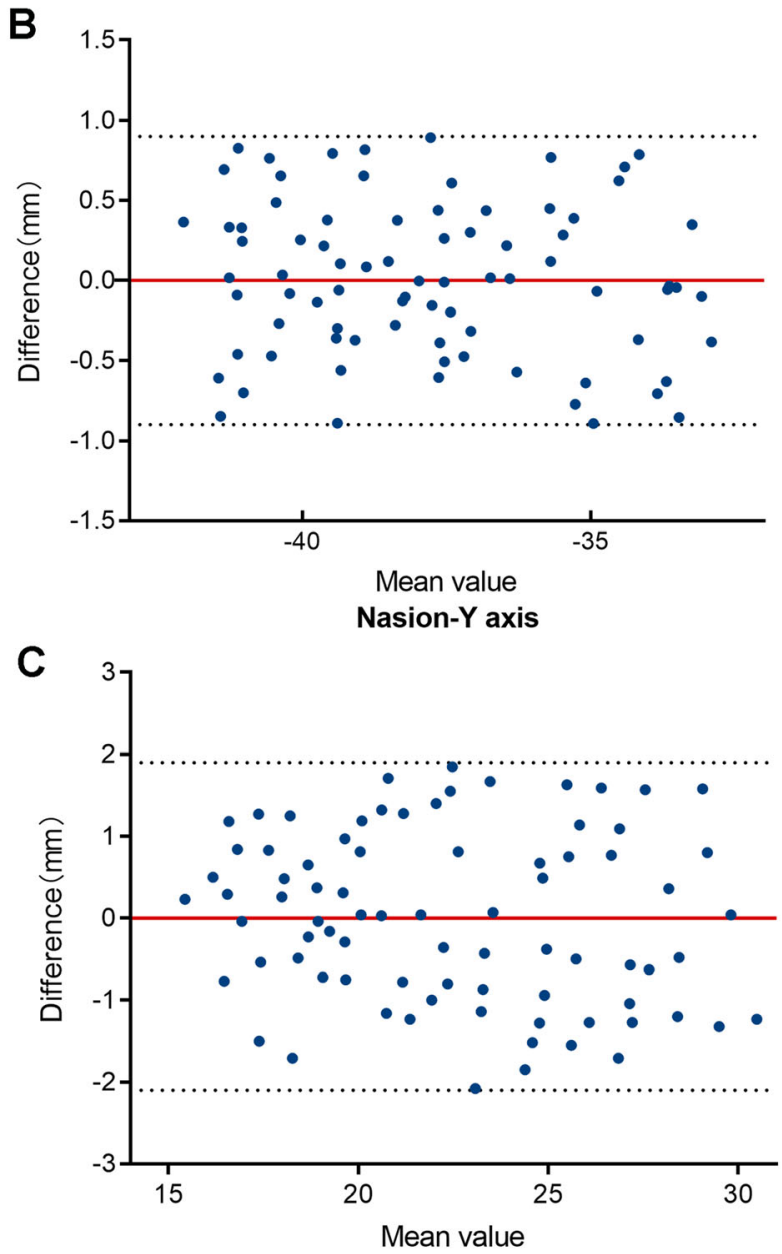

Supratip Break-Z axis

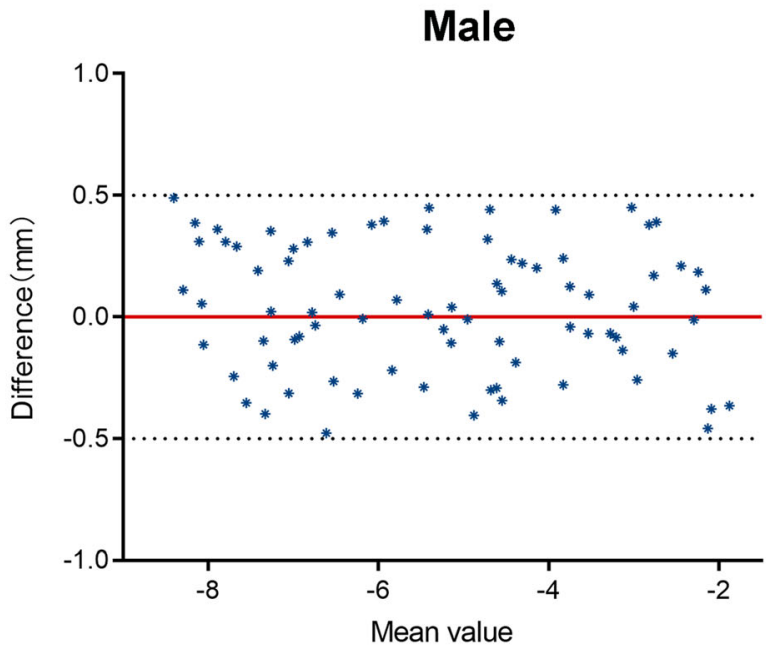

Pronasale- $X$ axis
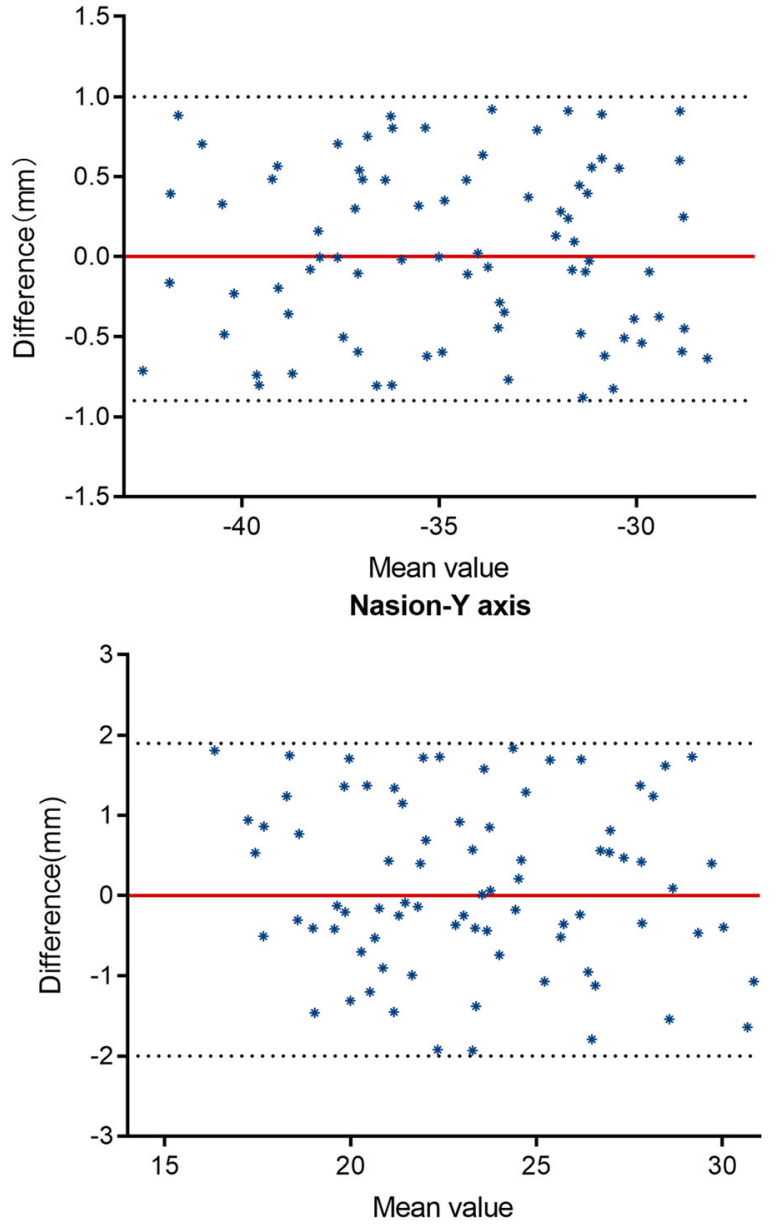

Suprtip Break-Z axis

Fig. 4 Reproducibility of representative landmarks identification between female and male (intra-rater) 
Table 2 Reproducibility of identified landmarks

\begin{tabular}{|c|c|c|c|c|c|c|c|c|c|c|c|c|}
\hline \multirow{3}{*}{$\begin{array}{l}\text { Method of assessment } \\
\text { Total } \\
\text { Reproducibility level (mm) }\end{array}$} & \multicolumn{6}{|c|}{ Intra-rater } & \multicolumn{6}{|c|}{ Inter-rater } \\
\hline & \multicolumn{6}{|c|}{$n=160$} & \multicolumn{6}{|c|}{$n=160$} \\
\hline & $<0.5$ & $0.05 \leq \mathrm{d}<1$ & $\mathrm{~d} \geq 1$ & & & & $<0.5$ & $0.05 \leq \mathrm{d}<1$ & $\mathrm{~d} \geq 1$ & & & \\
\hline Number of coordinates & 62 & 58 & 18 & & & & 43 & 58 & 37 & & & \\
\hline Percentage $(\%)$ & 45 & 42 & 13 & & & & 31.2 & 42 & 26.8 & & & \\
\hline Race & \multicolumn{3}{|c|}{ Caucasian $(n=80)$} & \multicolumn{3}{|c|}{ Asian $(n=80)$} & \multicolumn{3}{|c|}{ Caucasian $(n=80)$} & \multicolumn{3}{|c|}{ Asian $(n=80)$} \\
\hline Reproducibility level (mm) & $<0.5$ & $0.05 \leq \mathrm{d}<1$ & $\mathrm{~d} \geq 1$ & $<0.5$ & $0.05 \leq \mathrm{d}<1$ & $\mathrm{~d} \geq 1$ & $<0.5$ & $0.05 \leq \mathrm{d}<1$ & $\mathrm{~d} \geq 1$ & $<0.5$ & $0.05 \leq \mathrm{d}<1$ & $\mathrm{~d} \geq 1$ \\
\hline Number of coordinates & 63 & 52 & 23 & 51 & 59 & 28 & 42 & 56 & 40 & 43 & 57 & 38 \\
\hline Percentage $(\%)$ & 45.7 & 37.7 & 16.6 & 37 & 42.7 & 20.3 & 23.2 & 40.6 & 28.9 & 31.2 & 41.3 & 27.5 \\
\hline Gender & \multicolumn{3}{|c|}{ Female $(n=80)$} & \multicolumn{3}{|c|}{ Male $(n=80)$} & \multicolumn{3}{|c|}{ Female $(n=80)$} & \multicolumn{3}{|c|}{ Male $(n=80)$} \\
\hline Reproducibility level (mm) & $<0.5$ & $0.05 \leq \mathrm{d}<1$ & $\mathrm{~d} \geq 1$ & $<0.5$ & $0.05 \leq \mathrm{d}<1$ & $\mathrm{~d} \geq 1$ & $<0.5$ & $0.05 \leq \mathrm{d}<1$ & $\mathrm{~d} \geq 1$ & $<0.5$ & $0.05 \leq \mathrm{d}<1$ & $\mathrm{~d} \geq 1$ \\
\hline Number of coordinates & 58 & 52 & 28 & 62 & 52 & 24 & 41 & 55 & 42 & 42 & 59 & 37 \\
\hline Percentage $(\%)$ & 42 & 37.7 & 20.3 & 44.9 & 37.7 & 17.4 & 29.7 & 39.9 & 30.4 & 30.4 & 42.8 & 26.8 \\
\hline
\end{tabular}

Total number of coordinates $=138$

\section{The Reproducibility of Landmarks in Caucasian and Asian Participants}

Landmark accuracy for the Caucasian group ranged from 0.17 to $0.94 \mathrm{~mm}$ (intra-rater) and 0.20 to $1.38 \mathrm{~mm}$ (interrater) in the nose area, 0.44 to $0.61 \mathrm{~mm}$ (intra-rater) and 0.49 to $0.95 \mathrm{~mm}$ (inter-rater) in the eye area, 0.44 to 1.47 $\mathrm{mm}$ (intra-rater) and 0.52 to $1.75 \mathrm{~mm}$ (inter-rater) in the mouth area, 0.72 to $1.07 \mathrm{~mm}$ (intra-rater) and 1.19 to 1.63 $\mathrm{mm}$ (inter-rater) in the ear area, and 1.52 to $1.79 \mathrm{~mm}$ (intrarater) and 1.23 to $2.04 \mathrm{~mm}$ (inter-rater) in the other areas.

Landmark accuracy for the Asian group ranged from 0.20 to $1.38 \mathrm{~mm}$ (intra-rater) and 0.25 to $1.13 \mathrm{~mm}$ (interrater) in the nose area, 0.30 to $0.62 \mathrm{~mm}$ (intra-rater) and 0.54 to $0.85 \mathrm{~mm}$ (inter-rater) in the eye area, 0.47 to 1.52 $\mathrm{mm}$ (intra-rater) and 0.67 to $1.73 \mathrm{~mm}$ (inter-rater) in the mouth area, 0.86 to $0.97 \mathrm{~mm}$ (intra-rater) and 1.05 to 1.40 $\mathrm{mm}$ (inter-rater) in the ear area, and 1.23 to $2.04 \mathrm{~mm}$ (intrarater) and 1.43 to $2.21 \mathrm{~mm}$ (inter-rater) in the other areas.

Differences in landmark reproducibility between Caucasian and Asian were concentrated in nose tip, alare, and nostril area, including $\mathrm{Sn}, \mathrm{Cc}, \mathrm{Cm}, \mathrm{Al}$ right, $\mathrm{Al}$ left, Ac right, Nm of both sides, and Stb point. Several landmarks showed poor reproducibility in both Caucasians and Asians, namely Tri, Zy right, and Zy left. The landmarks with the most significant intra- and inter-group differences were $\mathrm{Zy}$ left with $0.8 \mathrm{~mm}$ in Caucasians and $\mathrm{Pa}$ right with $0.43 \mathrm{~mm}$ in Asians. Moreover, the measurement differences between intra- and inter-group assessment of landmarks in the Asian group were generally smaller than in the Caucasian group. The most and least reproducible landmarks in Asians were consistent with those in Caucasians (Table 3 \& Supplement Table 1).

\section{The Reproducibility of Landmarks in Female and Male Subgroups}

The accuracy of landmarks in the female subgroup ranged from 0.24 to $1.55 \mathrm{~mm}$ (intra-rater) and 0.32 to $1.88 \mathrm{~mm}$ (inter-rater) in the nose area, 0.31 to $0.53 \mathrm{~mm}$ (intra-rater) and 0.45 to $0.76 \mathrm{~mm}$ (inter-rater) in the eye area, 0.40 to $1.33 \mathrm{~mm}$ (intra-rater) and 0.53 to $1.83 \mathrm{~mm}$ (inter-rater) in the mouth area, 0.79 to $1.22 \mathrm{~mm}$ (intra-rater) and 1.40 to $1.99 \mathrm{~mm}$ (inter-rater) in the ear area, and 1.19 to $1.97 \mathrm{~mm}$ (intra-rater) and 1.17 to $2.25 \mathrm{~mm}$ (inter-rater) in the other areas.

The accuracy of landmarks in the male subgroup ranged from 0.21 to $1.45 \mathrm{~mm}$ (intra-rater) and 0.31 to $1.65 \mathrm{~mm}$ (inter-rater) in the nose area, 0.38 to $0.68 \mathrm{~mm}$ (intra-rater) and 0.49 to $0.85 \mathrm{~mm}$ (inter-rater) in the eye area, 0.41 to $1.08 \mathrm{~mm}$ (intra-rater) and 0.50 to $1.57 \mathrm{~mm}$ (inter-rater) in the mouth area, 0.83 to $1.14 \mathrm{~mm}$ (intra-rater) and 1.20 to $2.06 \mathrm{~mm}$ (inter-rater) in the ear area, and 1.28 to $1.45 \mathrm{~mm}$ (intra-rater) and 1.03 to $2.43 \mathrm{~mm}$ (inter-rater) in the other areas.

Compared to females, landmarks concentrating on the nose and mouth areas had higher reproducibility in males in intra-rater, while landmarks in the eye area had poorer reproducibility in males. Moreover, the deviations between intra- and inter-rater in males were smaller than in females.

We did not notice significant differences in the ranking of landmark reproducibility between genders overall, except for the Sellion right and Nostril base point left and 
Table 3 Ranking of facial softtissue landmarks in Caucasian and Asian in respect to their reproducibility in the three spatial planes

\begin{tabular}{|c|c|c|c|c|c|c|c|c|c|c|}
\hline \multirow{3}{*}{$\begin{array}{l}\text { Race } \\
\text { Area }\end{array}$} & \multicolumn{5}{|c|}{ Caucasian $(n=80)$} & \multicolumn{5}{|c|}{ Asian $(n=80)$} \\
\hline & \multirow[t]{2}{*}{ Landmarks } & \multicolumn{2}{|c|}{ Intra-rater } & \multicolumn{2}{|c|}{ Inter-rater } & \multirow[t]{2}{*}{ Landmarks } & \multicolumn{2}{|c|}{ Intra-rater } & \multicolumn{2}{|c|}{ Inter-rater } \\
\hline & & Mean & SD & Mean & $\mathrm{SD}$ & & Mean & SD & Mean & SD \\
\hline \multirow[t]{27}{*}{ Nose } & Nl 1 & 0.17 & 0.14 & 0.34 & 0.23 & Nl 1 & 0.20 & 0.15 & 0.25 & 0.22 \\
\hline & $\mathrm{Nl} \mathrm{r}$ & 0.17 & 0.12 & 0.43 & 0.45 & $\mathrm{Nl} \mathrm{r}$ & 0.24 & 0.21 & 0.28 & 0.26 \\
\hline & $\mathrm{Nb} 1$ & 0.20 & 0.14 & 0.48 & 0.49 & $\mathrm{Nb} \mathrm{r}$ & 0.25 & 0.17 & 0.30 & 0.23 \\
\hline & $\mathrm{Nb} \mathrm{r}$ & 0.21 & 0.26 & 0.48 & 0.15 & $\mathrm{Nb} 1$ & 0.27 & 0.30 & 0.38 & 0.28 \\
\hline & $\mathrm{Nt} r$ & 0.22 & 0.16 & 0.51 & 0.46 & Nt $\mathrm{r}$ & 0.30 & 0.27 & 0.39 & 0.36 \\
\hline & Nt 1 & 0.23 & 0.15 & 0.54 & 0.27 & Nt 1 & 0.43 & 0.36 & 0.49 & 0.34 \\
\hline & $\mathrm{Nm} 1$ & 0.25 & 0.19 & 0.55 & 0.33 & $\mathrm{Cc}$ & 0.43 & 0.38 & 0.54 & 0.42 \\
\hline & $\mathrm{Nm} \mathrm{r}$ & 0.26 & 0.19 & 0.55 & 0.49 & $\mathrm{Cm}$ & 0.43 & 0.28 & 0.60 & 0.47 \\
\hline & G & 0.31 & 0.21 & 0.61 & 0.38 & G & 0.44 & 0.38 & 0.63 & 0.48 \\
\hline & Prn & 0.31 & 0.21 & 0.71 & 0.55 & Prn & 0.44 & 0.32 & 0.63 & 0.52 \\
\hline & $\mathrm{Cm}$ & 0.35 & 0.24 & 0.72 & 0.53 & Al 1 & 0.45 & 0.57 & 0.65 & 0.53 \\
\hline & Stb & 0.39 & 0.29 & 0.79 & 0.56 & $\mathrm{Al} \mathrm{r}$ & 0.58 & 0.46 & 0.71 & 0.44 \\
\hline & TDP r & 0.44 & 0.40 & 0.84 & 0.65 & TDP r & 0.59 & 0.51 & 0.71 & 0.57 \\
\hline & TDP 1 & 0.44 & 0.39 & 0.85 & 0.62 & TDP 1 & 0.65 & 0.55 & 0.74 & 0.69 \\
\hline & $\mathrm{Se}$ & 0.48 & 0.40 & 0.88 & 0.75 & $\mathrm{Se}$ & 0.68 & 0.63 & 0.76 & 0.58 \\
\hline & $\mathrm{Cc}$ & 0.54 & 0.39 & 0.92 & 0.55 & $\mathrm{Nm} \mathrm{r}$ & 0.69 & 0.50 & 0.77 & 0.63 \\
\hline & Ac 1 & 0.64 & 0.47 & 0.93 & 0.72 & $\mathrm{Nm} 1$ & 0.71 & 0.60 & 0.78 & 0.57 \\
\hline & Holn & 0.67 & 0.47 & 1.00 & 0.69 & Holn & 0.78 & 0.70 & 0.98 & 0.73 \\
\hline & Ac $r$ & 0.68 & 0.50 & 1.01 & 0.75 & $A c r$ & 0.86 & 0.67 & 0.99 & 0.71 \\
\hline & Se'r & 0.69 & 0.54 & 1.03 & 0.72 & Se'r & 0.93 & 0.51 & 1.00 & 0.82 \\
\hline & Se'l & 0.72 & 0.69 & 1.06 & 0.74 & Se'l & 0.94 & 0.75 & 1.07 & 0.94 \\
\hline & $\mathrm{N}$ & 0.73 & 0.44 & 1.07 & 0.50 & $\mathrm{~N}$ & 0.95 & 0.60 & 1.08 & 0.86 \\
\hline & Al 1 & 0.75 & 0.61 & 1.09 & 0.68 & Ac 1 & 0.95 & 0.46 & 1.09 & 0.51 \\
\hline & $\mathrm{Al} \mathrm{r}$ & 0.75 & 0.55 & 1.11 & 0.64 & Stb & 1.04 & 0.62 & 1.10 & 0.71 \\
\hline & $\mathrm{Sn}$ & 0.83 & 0.57 & 1.15 & 0.58 & $\mathrm{Sn}$ & 1.04 & 0.86 & 1.11 & 0.83 \\
\hline & Ort 1 & 0.90 & 0.60 & 1.18 & 0.73 & Ort 1 & 1.04 & 0.97 & 1.13 & 0.78 \\
\hline & Ort $r$ & 0.94 & 0.66 & 1.20 & 0.87 & Ort $r$ & 1.11 & 0.69 & 1.13 & 0.74 \\
\hline \multirow[t]{4}{*}{ Eye } & En $r$ & 0.44 & 0.31 & 0.49 & 0.35 & En $r$ & 0.30 & 0.22 & 0.54 & 0.41 \\
\hline & En 1 & 0.49 & 0.34 & 0.65 & 0.51 & En 1 & 0.38 & 0.30 & 0.67 & 0.53 \\
\hline & $\mathrm{Em} \mathrm{r}$ & 0.54 & 0.30 & 0.66 & 0.30 & $\mathrm{Em} \mathrm{r}$ & 0.61 & 0.46 & 0.77 & 0.47 \\
\hline & Em 1 & 0.61 & 0.55 & 0.95 & 0.72 & Em 1 & 0.62 & 0.57 & 0.85 & 0.55 \\
\hline \multirow[t]{8}{*}{ Mouth } & Sto & 0.43 & 0.27 & 0.52 & 0.43 & Sto & 0.47 & 0.27 & 0.64 & 0.57 \\
\hline & $\mathrm{Li}$ & 0.43 & 0.36 & 0.58 & 0.32 & $\mathrm{Li}$ & 0.49 & 0.51 & 0.67 & 0.43 \\
\hline & Ls & 0.44 & 0.33 & 0.60 & 0.36 & Ls & 0.61 & 0.47 & 0.68 & 0.52 \\
\hline & $\mathrm{Sm}$ & 0.60 & 0.45 & 0.66 & 0.61 & $\mathrm{Sm}$ & 0.64 & 0.47 & 0.81 & 0.52 \\
\hline & S1 & 0.75 & 0.46 & 0.85 & 0.50 & $\mathrm{~S} 1$ & 0.86 & 0.64 & 0.95 & 0.48 \\
\hline & $\mathrm{Pg}$ & 0.98 & 0.72 & 1.45 & 0.65 & $\mathrm{Pg}$ & 1.21 & 1.03 & 1.31 & 0.78 \\
\hline & $\mathrm{Me}$ & 1.11 & 0.91 & 1.54 & 1.25 & $\mathrm{Me}$ & 1.50 & 1.14 & 1.63 & 1.03 \\
\hline & $\mathrm{C}$ & 1.47 & 0.84 & 1.75 & 1.22 & $\mathrm{C}$ & 1.52 & 0.94 & 1.73 & 0.69 \\
\hline \multirow[t]{4}{*}{ Ear } & $\operatorname{Trg} 1$ & 0.72 & 0.54 & 1.19 & 1.19 & $\operatorname{Trg} 1$ & 0.86 & 0.73 & 1.05 & 0.74 \\
\hline & Trg $\mathrm{r}$ & 0.87 & 0.68 & 1.29 & 0.67 & Trg r & 0.88 & 0.76 & 1.22 & 0.88 \\
\hline & $\mathrm{Pa} 1$ & 0.90 & 0.63 & 1.59 & 0.65 & $\mathrm{~Pa} 1$ & 0.89 & 0.55 & 1.29 & 0.92 \\
\hline & $\mathrm{Pa} \mathrm{r}$ & 1.07 & 0.69 & 1.63 & 0.68 & $\mathrm{Par}$ & 0.97 & 0.89 & 1.40 & 0.90 \\
\hline \multirow[t]{3}{*}{ Others } & Tri & 1.52 & 1.10 & 1.94 & 1.05 & Tri & 1.23 & 0.95 & 1.43 & 0.99 \\
\hline & Zy r & 1.62 & 0.97 & 2.00 & 1.02 & Zy r & 2.01 & 1.08 & 2.12 & 1.30 \\
\hline & Zy 1 & 1.79 & 1.38 & 2.59 & 1.19 & Zy 1 & 2.04 & 1.25 & 2.21 & 1.12 \\
\hline
\end{tabular}


Table 4 Ranking of facial softtissue landmarks in females and males in respect to their reproducibility in the three spatial planes

\begin{tabular}{|c|c|c|c|c|c|c|c|c|c|c|}
\hline \multirow{3}{*}{$\begin{array}{l}\text { Gender } \\
\text { Area }\end{array}$} & \multicolumn{5}{|c|}{$\operatorname{Female}(n=80)$} & \multicolumn{5}{|l|}{ Male $(n=80)$} \\
\hline & \multirow[t]{2}{*}{ Landmarks } & \multicolumn{2}{|c|}{ Intra-rater } & \multicolumn{2}{|c|}{ Inter-rater } & \multirow[t]{2}{*}{ Landmarks } & \multicolumn{2}{|c|}{ Intra-rater } & \multicolumn{2}{|c|}{ Inter-rater } \\
\hline & & Mean & SD & Mean & SD & & Mean & SD & Mean & SD \\
\hline \multirow[t]{27}{*}{ Nose } & Prn & 0.24 & 0.22 & 0.32 & 0.21 & Prn & 0.21 & 0.19 & 0.31 & 0.19 \\
\hline & $\mathrm{Cm}$ & 0.25 & 0.21 & 0.34 & 0.27 & $\mathrm{Cm}$ & 0.23 & 0.20 & 0.32 & 0.14 \\
\hline & Holn & 0.25 & 0.16 & 0.35 & 0.26 & Holn & 0.23 & 0.17 & 0.33 & 0.14 \\
\hline & TDP r & 0.30 & 0.22 & 0.35 & 0.25 & TDP r & 0.27 & 0.19 & 0.36 & 0.20 \\
\hline & TDP 1 & 0.34 & 0.91 & 0.56 & 0.48 & TDP 1 & 0.30 & 0.53 & 0.52 & 0.43 \\
\hline & $\mathrm{Se}$ & 0.38 & 0.38 & 0.59 & 0.19 & $\mathrm{Se}$ & 0.31 & 0.32 & 0.52 & 0.36 \\
\hline & G & 0.39 & 0.30 & 0.70 & 0.55 & G & 0.32 & 0.24 & 0.57 & 0.45 \\
\hline & Ac 1 & 0.38 & 0.93 & 0.77 & 0.52 & Ac 1 & 0.36 & 0.45 & 0.59 & 0.53 \\
\hline & Ac $r$ & 0.42 & 0.23 & 0.77 & 0.52 & Ac $r$ & 0.38 & 0.32 & 0.72 & 0.62 \\
\hline & Nt 1 & 0.43 & 0.33 & 0.79 & 0.57 & Nt 1 & 0.39 & 0.22 & 0.72 & 0.47 \\
\hline & $\mathrm{Nt} \mathrm{r}$ & 0.46 & 0.40 & 0.83 & 0.55 & $\mathrm{Nt} \mathrm{r}$ & 0.40 & 0.23 & 0.75 & 0.48 \\
\hline & Nl 1 & 0.47 & 0.43 & 0.84 & 0.59 & Nl 1 & 0.46 & 0.46 & 0.89 & 0.64 \\
\hline & $\mathrm{Nl} \mathrm{r}$ & 0.54 & 0.47 & 0.93 & 0.75 & $\mathrm{Nl} \mathrm{r}$ & 0.49 & 0.53 & 0.95 & 0.84 \\
\hline & Ort 1 & 0.57 & 0.44 & 0.94 & 0.62 & Ort 1 & 0.52 & 0.30 & 1.03 & 0.94 \\
\hline & Ort $r$ & 0.59 & 0.30 & 0.95 & 0.61 & Ort $r$ & 0.53 & 0.36 & 1.04 & 0.74 \\
\hline & $\mathrm{Cc}$ & 0.65 & 0.41 & 0.95 & 0.75 & $\mathrm{Cc}$ & 0.62 & 0.54 & 1.12 & 1.03 \\
\hline & $\mathrm{Sn}$ & 0.66 & 0.58 & 0.85 & 0.56 & $\mathrm{Sn}$ & 0.64 & 0.57 & 0.98 & 0.56 \\
\hline & Se'1 & 0.66 & 0.55 & 1.04 & 0.64 & $\mathrm{Se}^{‘} 1$ & 0.65 & 0.66 & 1.16 & 0.91 \\
\hline & Se'r & 0.71 & 0.57 & 1.08 & 0.65 & $\mathrm{Nb} 1$ & 0.73 & 0.49 & 1.20 & 0.49 \\
\hline & $\mathrm{Nb} 1$ & 0.73 & 0.80 & 1.13 & 0.63 & $\mathrm{Nb} \mathrm{r}$ & 0.73 & 0.61 & 1.25 & 0.86 \\
\hline & $\mathrm{Nb} \mathrm{r}$ & 0.75 & 0.65 & 1.21 & 1.01 & Se'r & 0.75 & 0.51 & 1.34 & 0.99 \\
\hline & $\mathrm{Nm} 1$ & 0.80 & 0.56 & 1.30 & 0.48 & $\mathrm{Nm} 1$ & 0.79 & 0.57 & 1.35 & 1.00 \\
\hline & $\mathrm{Nm} \mathrm{r}$ & 0.84 & 0.54 & 1.30 & 0.83 & $\mathrm{Nm} \mathrm{r}$ & 0.80 & 0.73 & 1.42 & 0.75 \\
\hline & $\mathrm{Al} \mathrm{r}$ & 0.85 & 0.56 & 1.57 & 1.02 & $\mathrm{Al} \mathrm{r}$ & 0.85 & 0.62 & 1.50 & 1.12 \\
\hline & Al 1 & 0.86 & 0.80 & 1.61 & 1.03 & $\mathrm{Al} 1$ & 0.86 & 0.54 & 1.51 & 1.01 \\
\hline & $\mathrm{N}$ & 0.90 & 0.60 & 1.52 & 0.69 & $\mathrm{~N}$ & 0.99 & 0.84 & 1.35 & 0.89 \\
\hline & Stb & 1.55 & 1.01 & 1.88 & 0.91 & Stb & 1.45 & 0.92 & 1.65 & 0.76 \\
\hline \multirow[t]{4}{*}{ Eye } & Em 1 & 0.31 & 0.26 & 0.45 & 0.35 & Em 1 & 0.38 & 0.29 & 0.49 & 0.36 \\
\hline & $\mathrm{Em} \mathrm{r}$ & 0.39 & 0.36 & 0.54 & 0.35 & $\mathrm{Em} \mathrm{r}$ & 0.43 & 0.32 & 0.56 & 0.53 \\
\hline & En $r$ & 0.48 & 0.40 & 0.71 & 0.60 & En $r$ & 0.67 & 0.50 & 0.79 & 0.82 \\
\hline & En 1 & 0.53 & 0.44 & 0.76 & 0.67 & En 1 & 0.68 & 0.55 & 0.85 & 0.48 \\
\hline \multirow[t]{8}{*}{ Mouth } & Ls & 0.43 & 0.36 & 0.53 & 0.42 & Ls & 0.41 & 0.29 & 0.50 & 0.70 \\
\hline & $\mathrm{Li}$ & 0.52 & 0.48 & 0.62 & 0.32 & $\mathrm{Li}$ & 0.44 & 0.28 & 0.52 & 0.45 \\
\hline & Sto & 0.59 & 0.46 & 0.68 & 0.50 & Sto & 0.45 & 0.40 & 0.54 & 0.27 \\
\hline & $\mathrm{Me}$ & 0.60 & 0.55 & 0.82 & 0.59 & $\mathrm{Me}$ & 0.50 & 0.45 & 0.68 & 0.49 \\
\hline & S1 & 0.72 & 0.60 & 1.04 & 0.81 & $\mathrm{Sl}$ & 0.70 & 0.54 & 0.99 & 0.58 \\
\hline & $\mathrm{Pg}$ & 0.73 & 0.41 & 1.09 & 1.19 & $\mathrm{Pg}$ & 0.70 & 0.36 & 1.04 & 0.75 \\
\hline & $\mathrm{Sm}$ & 1.13 & 1.01 & 1.51 & 1.04 & $\mathrm{Sm}$ & 1.02 & 0.71 & 1.36 & 0.73 \\
\hline & $\mathrm{C}$ & 1.33 & 0.83 & 1.83 & 1.17 & $\mathrm{C}$ & 1.08 & 0.82 & 1.57 & 0.99 \\
\hline \multirow[t]{4}{*}{ Ear } & $\mathrm{Pa} 1$ & 0.79 & 0.52 & 1.40 & 1.07 & $\mathrm{~Pa} 1$ & 0.78 & 0.64 & 1.12 & 0.66 \\
\hline & $\mathrm{Pa} \mathrm{r}$ & 0.87 & 0.71 & 1.65 & 0.95 & $\mathrm{~Pa} \mathrm{r}$ & 0.84 & 0.65 & 1.13 & 0.66 \\
\hline & $\operatorname{Trg} r$ & 1.04 & 0.63 & 1.42 & 0.62 & $\operatorname{Trg} r$ & 0.87 & 0.66 & 1.15 & 0.68 \\
\hline & $\operatorname{Trg} 1$ & 1.22 & 0.68 & 1.99 & 0.93 & $\operatorname{Trg} 1$ & 1.14 & 0.97 & 1.45 & 0.91 \\
\hline \multirow[t]{3}{*}{ Others } & Tri & 1.53 & 1.07 & 1.64 & 0.95 & Tri & 1.50 & 0.93 & 1.58 & 0.89 \\
\hline & Zy r & 1.87 & 1.35 & 2.09 & 1.27 & Zy r & 1.64 & 1.06 & 1.92 & 0.99 \\
\hline & Zy 1 & 1.97 & 1.49 & 2.25 & 1.36 & Zy 1 & 1.77 & 1.17 & 2.27 & 0.82 \\
\hline
\end{tabular}


right. Among both female and male groups, Pronasale (prn) was the most reproducible landmark, while Zygion left was the least reproducible landmark (Table 4 and Supplement Table 1).

Some landmarks differed in the reproducibility levels in intra-rater and inter-rater assessments as follows: $\mathrm{Cm}$ and Stb were highly reproducible $(<0.5 \mathrm{~mm})$ in intra-rater and moderately $(<1 \mathrm{~mm})$ in inter-rater assessment for the Caucasian sample. In Asian sample, Se right and Se left were moderately reproducible $(<0.5 \mathrm{~mm})$ in intra-rater and poorly reproducible $(>1 \mathrm{~mm})$ in inter-rater assessment.

\section{The Representative Landmarks in Ethnic and Gender Subgroups}

Bland-Altman plots are used to illustrate the consistency level between the values of each $3 \mathrm{D}$ coordinate $(\mathrm{X}, \mathrm{Y}$, and $\mathrm{Z})$ for the facial landmarks. Some representative coordinates of facial landmarks are given in Fig. 3 to illustrate the high, moderate, and low levels of consistency between the measurements obtained from intra-rater assessment of the ethnic subgroup. Figure $3 \mathrm{a}$ indicates that the landmark Columella $(\mathrm{Cm})$ was highly reproducible $(<0.5 \mathrm{~mm})$ in the $\mathrm{X}$-plane for Caucasians and Asians. Figure $3 \mathrm{~b}$ indicates that the landmark Menton (M) was moderately reproducible $(>0.5 \mathrm{~mm})$ in the $\mathrm{Y}$-plane. Figure $3 \mathrm{c}$ indicates that the landmark Trichion (Tri) was poorly reproducible $(>1$ $\mathrm{mm}$ ) in the Z-plane. Figure 4 exhibits some representative coordinates of the measurements obtained from the interrater assessment for facial landmarks in gender subgroup. Figure $4 \mathrm{a}$ indicates that the landmark Pronasale (Prn) was highly reproducible $(<0.5 \mathrm{~mm})$ in the $\mathrm{X}$-plane for both females and males. Figure $4 \mathrm{~b}$ indicates that the landmark Nasion $(\mathrm{N})$ was moderately reproducible $(>0.5 \mathrm{~mm})$ in the Y-plane. Figure $4 c$ indicates that the landmark Supratip break point $(\mathrm{Stb})$ was poorly reproducible in the Z-plane $(>1 \mathrm{~mm})$.

\section{Discussion}

Facial soft-tissue landmarks and their anthropometric measurements play an important role in the clinical practice of numerous medical disciplines, particularly in reconstructive and aesthetic plastic surgery, otorhinolaryngology along with oral and maxillofacial surgery. Landmark-based cephalometric measurements facilitate diagnosis, counseling, and treatment planning, as well as an objective evaluation of a therapeutic outcome. The reproducibility of facial soft-tissue landmarks has been studied in detail on 2D photography and several classic facial landmarks have been validated for their utility in 3D surface imaging $[15,21,23]$.
In the current study, we identified several non-traditional facial soft landmarks based on daily clinical experience and validated all 46 landmarks in gender-identical Caucasian and Asian samples. We explored the reproducibility of these soft-tissue landmarks on 3D facial images of our two ethnic groups. The reproducibility of facial landmarks has been validated in the three spatial planes and our measurements showed that the majority coordinates in $x, y, z$ axes of the 46 landmarks are reproducible to less than $1 \mathrm{~mm}$, which is clinically acceptable (87\% intra-rater and $73.2 \%$ inter-rater). The reproducibility of the intra-rater evaluation was higher than that of the inter-rater.

Based on our measurements in different intra-rater and inter-rater sessions, we inferred the following criteria involved in facial landmarks' reproducibility. First, the clear description and definition of landmarks. Second, the morphology and contour of the facial area in which the landmark is located. Landmarks located in more projecting or well-defined areas have a higher reproducibility. For instance, Prn and TDP are more reproducible than $\mathrm{Zy}$, which is located on a flatter site. Third, features and characteristics of landmarks. Landmarks with distinctive features usually have a higher reproducibility. Four, the ethnicities and genders with different facial features and characteristics. Five, rater dependency. Examples include level of attention, discipline and consistency, proficiency in 3D imaging software and knowledge of facial anatomy. Six, the quality of $3 \mathrm{D}$ imaging. The landmarks on the artifact-free and defect-free areas are more reproducible.

In addition, the reproducibility of our landmarks varies in the three planes. For example, certain landmarks are harder to locate accurately on one axis than on the other two. Previous studies have reported similar results [24, 25]. Medelnik et al. attribute this bias to the position of landmark relative to the individual's facial morphology [26]. The poorly reproducible landmarks are mostly concentrated on nose alare, chin, Trichion, and Zygion. Raters may not be able to find a suitable reference point in less clearly demarcated areas. Hair-bearing skin areas, such as the hairline, usually have lower reproducibility [27]. Moreover, it has been reported that the patient's head occasionally needs to be tilted back slightly to ensure data quality in nose and chin area, which complicates ensuring a consistent recording position [28]. Therefore, precautions should be taken in the preparation of the 3DSI to minimize hair and sitting-induced errors and to make landmark identification more precise.

Some landmarks and coordinates vary by race. Landmarks distributed in the nasal tip and nostrils, such as $\mathrm{Nl}$, $\mathrm{Nb}, \mathrm{Nt}, \mathrm{Nm}$, TDP, Stb, and Prn, are more reproducible in Caucasians. Nasal anatomical features of Caucasians differ from those of Asians. A previous study found that the 
Caucasian descent typically has relatively thick nasal skin, straighter dorsum, more pronounced nasal tip, and teardrop shape nostrils. Correspondingly, the bony vault in Asians is usually wide and short. The dorsal aesthetic lines were not clearly defined, resulting in a less well-defined TDP. The nasal tip was widened with wide alar bases. The nasal length was shortened, with diminished tip projection and horizontally oriented nostrils [29]. These factors could impact the raters to identify the nasal tip and the nostril axis and to locate the landmarks associated with these regions in Caucasians. Thus, before clinical use of a 3D landmark-based study, the reliability of the measurements for different ethnicities would need to be investigated separately.

We also observed slight gender-dependent differences in landmark placement accuracy. In intra-and inter-rater reproducibility assessment, the landmark $\mathrm{Zy}$ on both sides of the $\mathrm{x}$-axis produced fewer errors in males. Our observation that males have larger and more pronounced zygomatic bone than females, which facilitates the rater to position $\mathrm{Zy}$ on the $\mathrm{x}$-axis. Previous anthropometric studies have shown that males have more angular chin and jawbones than females. Male's jaws are on average 17\% higher vertical and have more lateral fullness, which may affect the 3D placement of landmarks in these areas [30]. These features may make it easier to locate the landmarks $\mathrm{Ls}, \mathrm{Li}, \mathrm{Me}$, and $\mathrm{C}$.

In terms of device technology, it should be noted that Vectra XT 3D Surface Imaging System has some imperfections in 3D modeling of hair-bearing skin areas and complex structures, making it prone to artifacts and distortions. Nevertheless, despite its limitations, photogrammetry still has an irreplaceable role and potential for widespread application in predicting soft-tissue contours and monitoring treatment progress, especially for patients undergoing complex rhinoplasty and maxillofacial plastic surgery, as well as consultations for orthodontic treatment or orthognathic surgery.

\section{Conclusion}

Before being widely used in clinics, the reproducibility of each facial landmark should be verified on the $\mathrm{x}, \mathrm{y}$, and $\mathrm{z}$ three planes. In order to obtain good reproducibility, the rater placing landmarks must clearly define and thoroughly understand their definitions. Landmarks located at different positions on the face have broad variation in reproducible levels; the landmarks placed on clear features and boundaries area have higher reproducibility than those placed on flat or a gently curved plane. This may be related to gender and ethnic differences in facial morphology, leading to variations in the reproducibility of certain landmarks. It is also essential for raters to have sufficient knowledge of facial anatomy and proficiency in 3D images to improve the reproducibility of landmarks. In this study, the majority of the 138 coordinates from 46 facial landmarks had a reproducibility of less than $1 \mathrm{~mm}$, which is clinically acceptable (87\% intra-examiner and $73.2 \%$ inter-examiner). Therefore, 3D scanning with Vectra XT 3D Surface Imaging System meets the requirement of cephalometry based on facial soft-tissue landmarks in daily clinical practice. Meanwhile, race and gender reproducibility bias of the different landmarks should be taken into account during the evaluation.

Supplementary Information The online version contains supplementary material available at https://doi.org/10.1007/s00266021-02642-4.

Acknowledgements We greatly thank the China Scholarship Council (CSC) for supporting the work of Zhouxiao $\mathrm{Li}$ (No. 201708320345).

Funding Open Access funding enabled and organized by Projekt DEAL.

\section{Declarations}

Conflict of interest All authors declare that they have no competing interests. None of the authors is shareholders in one of the named companies whose medical devices, hardware, and software were used in the study, nor did they have any other financial interest in the named company.

Informed consents Written informed consents were obtained from all participants correspond with the Declaration of Helsinki protocols (1996). This study was performed in line with local laws and good clinical practice (1996) and approved by the Ethics Committee of the Ludwig-Maximilians-University Munich (Reference Number 266-13).

Open Access This article is licensed under a Creative Commons Attribution 4.0 International License, which permits use, sharing, adaptation, distribution and reproduction in any medium or format, as long as you give appropriate credit to the original author(s) and the source, provide a link to the Creative Commons licence, and indicate if changes were made. The images or other third party material in this article are included in the article's Creative Commons licence, unless indicated otherwise in a credit line to the material. If material is not included in the article's Creative Commons licence and your intended use is not permitted by statutory regulation or exceeds the permitted use, you will need to obtain permission directly from the copyright holder. To view a copy of this licence, visit http://creativecommons. org/licenses/by/4.0/.

\section{References}

1. Feng Z, Guiyang Z, Weijie F et al (2018) Application of 3D printing technology in RGPCL simulation fitting. Med Hypotheses 113(1):74-76

2. Garyfalia L, Peter C, Grant SH et al (2016) Evolution of preoperative rhinoplasty consult by computer imaging. Facial Plast Surg 32(1):80-87 
3. Farkas LG (1996) Accuracy of anthropometric measurements: past, present, and future. Cleft Palate Craniofac J 33:10-18

4. Savran A, Alyüz N, Dibeklioğlu H et al (2008) Bosphorus database for 3D face analysis. Biometrics and identity management. Springer, Berlin Germany

5. Xi Z, Dell AE, Liming C et al (2011) Accurate landmarking of three-dimensional facial data in the presence of facial expressions and occlusions using a three-dimensional statistical facial feature model. IEEE Trans Syst, Man, Cybern, Part B: Cybern 41(5):1417-1428

6. Koban KC, Perko P, Etzel L et al (2020) Validation of two handheld devices against a non-portable three-dimensional surface scanner and assessment of potential use for intraoperative facial imaging. J Plast Reconstr Aesthet Surg 73(1):141-148

7. Bechtold TE, Göz TG, Schaupp E et al (2012) Integration of a maxillary model into facial surface stereophotogrammetry. J Orofac Orthop 73:126-137

8. White JD, Castrillon AO, Virgo C et al (2020) Sources of variation in the 3dMDface and Vectra H1 3D facial imaging systems. Sci Rep 10(1):4443

9. Daniele G, Valentina P, Annalisa C et al (2018) Are portable stereophotogrammetric devices reliable in facial imaging? A validation study of VECTRA H1 Device? J Oral Maxillofac Surg 76(8):1772-1784

10. Proffit WR, White RP, Sarver DM (2003) Contemporary treatment of dentofacial deformity. St. Louis: CV Mosby Co

11. Koudelovea J, Bruzek J, Caganova V et al (2015) Development of facial sexual dimorphism in children aged between 12 and 15 years: a three-dimensional longitudinal study. Orthod Craniofac Res 18:175

12. Pucciarelli V, Bertoli S, Codari M et al (2017) The face of Glut1DS patients: A 3D craniofacial morphometric analysis. Clin Anat 30:644

13. Baik HS, Jeon JM, Lee HJ (2007) Facial soft-tissue analysis of Korean adults with normal occlusion using a 3-dimensional laser scanner. Am J Orthod Dentofacial Orthop 131:759-766

14. Dindaroğlu F, Kutlu P, Duran GS et al (2016) Accuracy and reliability of 3D stereophotogrammetry: a comparison to direct anthropometry and 2D photogrammetry. Angle Orthod 86(3):487-494

15. Khambay B, Nairn N, Bell A et al (2008) Validation and reproducibility of a high-resolution three-dimensional facial imaging system. Br J Oral Maxillofac Surg 46(1):27-32

16. Metzler P, Sun Y, Zemann W et al (2014) Validity of the 3D VECTRA photogrammetric surface imaging system for craniomaxillofacial anthropometric measurements. Oral Maxillofac Surg 18:297-304
17. Toma AM (2007) A three-dimensional analysis of facial morphology using laser-scan imaging technology. Thesis (MPhil). Wales, UK: Applied Clinical Research and Public Health, Dental School, Cardiff University

18. Farkas LG (1994) Examination. In: Farkas LG (ed) Anthropometry of the Head and Face, 2nd edn. Raven Press, New York, pp 3-56

19. Swennen GR et al (2006) Three-dimensional cephalometry: a color altas and manual. Springer Press

20. Jamilian A, Darnahal A, Hamedi R et al (2016) Photogrammetric analysis of facial profile in Persian adults. Gen Dent 64(2):52-55

21. Toma AM, Zhurov A, Playle R et al (2009) Reproducibility of facial soft tissue landmarks on 3D laser-scanned facial image. Orthod Craniofac Res 12(1):33-42

22. Fink M, Medelnik J, Strobel K (2014) Metric precision via softtissue landmarks in three-dimensional structured-light scans of human faces. J Orofac Orthop 75(2):133-143

23. Ferrario VF, Sforza C, Poggio CE, Serrao G (1996) Facial threedimensional morphometry. Am J Orthod Dentofacial Orthop 109:86-93

24. De Oliveira AE, Cevidanes LH, Phillips C et al (2009) Observer reliability of three-dimensional cephalometric landmark identification on cone-beam computerized tomography. Oral Surg Oral Med Oral Pathol Oral Radiol Endod 107:256-265

25. Park SH, Yu HS, Kim KD et al (2006) A proposal for a new analysis of craniofacial morphology by 3-dimensional computed tomography. Am J Orthod Dentofacial Orthop 129:600.e23600.e34

26. Medelnik J, Hertrich K, Steinhäuser-Andresen S et al (2011) Accuracy of anatomical landmark identification using different CBCT- and MSCT-based 3D images. An in vitro study. J Orofac Orthop 72:261-278

27. Berneburg M, Schubert C, Einem C et al (2010) The reproducibility of landmarks on three-dimensional images of 4- to 6-year-old children. J Orofac Orthop 71:256-264

28. Heike CL, Upson K, Stuhaug E, Weinberg SM (2010) 3D digital stereophotogrammetry: a practical guide to facial image acquisition. Head Face Med 6:18

29. Villanueva NL, Afrooz PN, Carboy JA, Rohrich Rod J et al (2019) Nasal analysis: considerations for ethnic variation. Plast Reconstr Surg 143(6):1179e-1188e

30. Ousterhout DK (2011) Dr. Paul tessier and facial skeletal masculinization. Ann Plast Surg 67(6):S10-5

Publisher's Note Springer Nature remains neutral with regard to jurisdictional claims in published maps and institutional affiliations. 